\title{
Factors associated with residual urine volume preservation in patients undergoing hemodialysis for end-stage kidney disease in Kinshasa
}

Vieux Momeme Mokoli ${ }^{1,2^{*}}$, Ernest Kiswaya Sumaili ${ }^{1}$, François Bompeka Lepira ${ }^{1}$, Fiston Ikwa Ndol Mbutiwi ${ }^{5}$, Jean Robert Rissassy Makulo ${ }^{1,2}$, Justine Busanga Bukabau, Patrick Parmba Izeidi', Jeannine Losa Luse ${ }^{3}$, Stéphane Kalambay Mukendi ${ }^{3}$, Désiré Kulimba Mashinda ${ }^{4}$ and Nazaire Mangani Nseka ${ }^{1,3}$

\begin{abstract}
Background: Decreased residual urine volume (RUV) is associated with higher mortality in hemodialysis (HD). However, few studies have examined RUV in patients on HD in Sub-Saharan Africa. The aim of this study was to identify predictors of RUV among incident hemodialysis patients in Kinshasa.

Methods: This historical cohort study enrolled 250 patients with ESRD undergoing hemodialysis between January 2007 and July 2013 in two hemodialysis centers in Kinshasa. RUV were collected over $24 \mathrm{~h}$ at the initiation of HD and 6 and 12 months later during the interdialytic period. We compared the baseline characteristics of the patients according to their initial RUV ( $\leq 500 \mathrm{ml} /$ day vs $>500 \mathrm{ml} /$ day) using Student's t, Mann-Whitney $\mathrm{U}$ and Chi2 tests. Linear mixed-effects models were used to search for predictors of decreased RUV by adding potentially predictive baseline covariates of the evolution of RUV to the effect of time: age, sex, diabetes mellitus, hypertension, diastolic blood pressure, diuretics, angiotensin conversion enzyme inhibitors (ACEI), angiotensin receptor blockers, hypovolemia, chronic tubulointerstitial nephropathy, left ventricular hypertrophy and initial hemodialysis characteristic. A value of $p<0.05$ was considered the threshold of statistical significance.
\end{abstract}

Results: The majority of hemodialysis patients were male (68.8\%, sex ratio 2.2), with a mean age of $52.5 \pm 12.3$ years. The population's RUV decreased with time, but with a slight deceleration. The mean RUV values were $680 \pm 537 \mathrm{ml} /$ day, $558 \pm 442 \mathrm{ml} /$ day and $499 \pm 475 \mathrm{ml} /$ day, respectively, at the initiation of HD and at 6 and 12 months later. The use of ACEl at the initiation of HD (beta coefficient 219.5, $p<0.001$ ) and the presence of chronic tubulointerstitial nephropathy (beta coefficient 291.8, $p=0.007$ ) were significantly associated with RUV preservation over time. In contrast, the presence of left ventricular hypertrophy at the initiation of HD was significantly associated with decreased RUV over time (beta coefficient $-133.9, p=0.029$ ).

Conclusions: Among incident hemodialysis patients, the use of ACEI, the presence of chronic tubulointerstitial nephropathy and reduced left ventricular hypertrophy are associated with greater RUV preservation in the first year of dialysis.

\footnotetext{
* Correspondence: vieux.mokoli@gmail.com

'Division of Nephrology, University of Kinshasa, Kinshasa, Democratic

Republic of the Congo

${ }^{2}$ Hemodialysis Unit of Ngaliema Medical Center, Kinshasa, Democratic

Republic of the Congo

Full list of author information is available at the end of the article
}

(c) The Author(s). 2018 Open Access This article is distributed under the terms of the Creative Commons Attribution 4.0 International License (http://creativecommons.org/licenses/by/4.0/), which permits unrestricted use, distribution, and reproduction in any medium, provided you give appropriate credit to the original author(s) and the source, provide a link to the Creative Commons license, and indicate if changes were made. The Creative Commons Public Domain Dedication waiver (http://creativecommons.org/publicdomain/zero/1.0/) applies to the data made available in this article, unless otherwise stated. 


\section{Background}

In Kinshasa, the capital City of the Democratic Republic of the Congo, the overall prevalence of chronic kidney disease (CKD) in the general population is estimated to be $12.4 \%$, with $0.2 \%$ of individuals with end-stage renal disease (ESRD) [1]. Late referral is the underlying cause for the admission of most patients with ESRD. For these patients, renal replacement therapy, including hemodialysis (HD), guarantees better survival and good quality of life. Among the criteria for effective HD, the preservation of residual kidney function (RKF) or residual urine volume (RUV) plays an important role in contributing to the survival and quality of life of hemodialysis patients [2-4]. Patient demographic characteristics, comorbid disease and characteristics of dialysis treatment have been associated with a faster decline in RUV in dialysis patients. Among these factors, we identified increasing age $[4,5]$, female sex [4-7], diabetes $[4,5,8]$, hypertension $[6,8,9]$, left ventricular hypertrophy (LVH) [10], congestive heart failure $[4,5]$, proteinuria [11], frequent dialysis [7, 12-14], intradialytic hypotension $[4,5,7,11]$ and biocompatible membrane $[4,15]$ as relevant. In this context, the National Kidney Foundation's Kidney Disease Outcome Quality Initiative (KDOQI) guidelines recommended the implementation of RKF preservation strategies in dialysis patients using RUV as a surrogate indicator [16, 17]. These strategies include the use of angiotensin-converting enzyme inhibitors (ACE) [18], angiotensin receptor blockers (ARB) [19] and diuretics [20]; the control of hypovolemia [21], obesity [22] and high blood pressure; the avoidance of nonsteroidal anti-inflammatory drugs, aminoglycosides and radiographic contrast agents [23]; the reduction of LVH [10]; a lower dose of dialysis [13]; the use of biocompatible dialysates and dialyzers and bicarbonate rather than acetate; and the early initiation of $\operatorname{HD}[5,24,25]$. It is now accepted that the use of ultrapure water in HD helps preserve RKF [26]. Although the definition of the RKF varies across studies, RUV may emerge as a pragmatic alternative to calculate RKF [27]. Therefore, the search for factors that may contribute to the preservation of RUV in resource-limited settings should be a priority to improve the practice of HD. In sub-Saharan Africa, including the Democratic Republic of the Congo (DRC), there are no studies examining the predictors of RUV in patients undergoing HD. The present study assessed factors that may contribute to the preservation of residual urine volume in HD patients in Kinshasa.

\section{Methods}

This historical cohort study enrolled 250 patients with ESRD undergoing HD in two HD centers in Kinshasa (Ngaliema Medical Center and Afia Medical Center) between January 2007 and July 2013. These facilities own Fresenius 4008B, $4008 \mathrm{~s}$ and, since 2010, $5008 \mathrm{~s}$ machines and a water treatment unit with double-pass reverse osmosis, which ensures the production of ultrapure water. Patients were alternately treated with hemodialysis (HD) or hemodiafiltration (HDF). The dialyzers used were made of polysulfone or high-flux membranes such as Helixone Plus High-flux.

All patients with ESRD admitted for HD who received at least 4 weeks of renal replacement therapy were included in this study. Socio-demographic and anthropometric parameters of interest were age, gender, weight and height. For clinical parameters, systolic blood pressure (SBP) and diastolic blood pressure (DBP) were measured before the first session of HD using an electronic sphygmomanometer. Pulse pressure (PP) was calculated as the difference between SBP and DBP. The current medical treatment and complications at the initiation of HD were recorded on the appropriate form. Twentyfour-hour urine collection was used to measure RUV before beginning $\mathrm{HD}$, and a similar urine collection protocol was used on days between dialysis 6 and 12 months later. The definition of volemia combined measurements of venous pressure, blood pressure and weight gain. For the evaluation of central venous pressure, we first performed a clinical assessment by placing the patient lying at $45^{\circ}$ from the bed plane and appreciating the visibility of the jugular vein for a clinical estimation of $5-7 \mathrm{~cm} \mathrm{H} 2 \mathrm{O}$. Patients with a value greater than $7 \mathrm{~cm} \mathrm{H} 2 \mathrm{O}$ benefited from the measure of central venous pressure. Hypervolemia was defined as a central venous pressure $\geq 13 \mathrm{~cm} \mathrm{H} 2 \mathrm{O}$ [28]. If the clinical estimate was below $5 \mathrm{~cm} \mathrm{H} 2 \mathrm{O}$ with decreased weight and blood pressure, patients were considered hypovolemic. Left ventricular hypertrophy (LVH) was noted when the thickness of the interventricular septum and posterior left ventricular wall was greater than $11 \mathrm{~mm}$ at the end of diastole or when the left ventricular mass was greater than or equal to $120 \mathrm{~g} / \mathrm{m} 2$ [29]. Heart failure was defined on the basis of signs of pulmonary and peripheral stasis and a systolic ejection fraction of the left ventricle $<40 \%$ [30]. Chronic tubulointerstitial nephropathy was defined as End stage renal disease with the absence or modest degree of the two principal hallmarks of glomerular and vascular diseases of the kidney: salt retention, manifested by edema and hypertension; and proteinuria, which usually is modest and less than 1 to $2 \mathrm{~g} / \mathrm{d}$ in TIN.

\section{Statistical analysis}

The continuous variables are presented as an average with the standard deviation or median values and interquartile range (IQR), and the categorical variables are presented in the form of absolute frequency (percentage).

We compared the baseline characteristics of the patients according to their initial RUVs $(\leq 500 \mathrm{ml} /$ day vs $>500 \mathrm{ml} /$ 
day) using Student's t, Mann-Whitney U and Chi2 tests, as appropriated.

We described the average populational and individual evolution of RUV repeated-measurements by graphical analysis. The RUV medians (IQR) at each assessment time are presented based on baseline categorical covariates. For the continuous covariates, the Pearson correlation coefficient $\mathrm{r}$ was presented.

For modelization, we first chose a linear mixed-effects model to analyze the effect of time alone on the decline in RUV (model 1). As the course of RUV mainly showed a non-linear pattern in the repeated-measurements analyses, this model allows a random intercept, a random slope and the quadratic term of time in fixed effects, with an unstructured variance-covariance matrix. Next, we constructed model 2 based on model 1 by adding baseline covariates as potential predictors of the evolution of RUV: age (years), sex (female vs male), diabetes mellitus (yes vs no), hypertension (yes vs no), diastolic blood pressure ( $\mathrm{mm} \mathrm{Hg}$ ), the use of diuretics (yes vs no), ACE inhibitors (yes vs no) and angiotensin receptor blockers (ARB, yes vs no), hypovolemia (yes vs no), Chronic tubulointerstitial nephropathy (yes vs no), left ventricular hypertrophy (yes vs no) and initial hemodialysis characteristic ( $\geq 3$ vs $\leq 2$ times weekly). Congestive heart failure was not chosen because of its correlation with left ventricular hypertrophy. Proteinuria was not tested because of the importance of missing data. In addition, using model 2 (main model), we tested other models, each time adding a term of time interactions with each of the baseline covariates tested in model 2, with the exception of age. For each of these models, only the variables that were significantly associated with the evolution of RUV were included in the final models. We conducted the residuals analysis to ensure the validity of the model assumptions, and plotted the predicted marginal means of RUV over time. Finally, we performed a sensitivity analysis based on the final model 2 by fitting a model allowing the quadratic term of time as a random effect (individuals curves) and those with the exchangeable and autoregressive residual $\mathrm{AR}(1)$ covariance structures instead of the unstructured covariance matrix. We used the Akaike information criterion (AIC) to compare these models.

SPSS software version 24 and Stata/IC version 14.2 (StataCorp LP, College Station, Texas, USA) were used to carry out all statistical analyses. A value of $p<0.05$ was considered the threshold of statistical significance.

The Ethics Committee of the Faculty of Medicine, University of Kinshasa approved the implementation of this study.

\section{Results}

Baseline characteristics of the patients

The majority of dialysis patients were male $(68.8 \%$, sex ratio 2.2 ), with a mean age of $52.5 \pm 12.3$ years (Table 1 ).
The initiation of HD for the entire group corresponded to a median (IQR) estimated glomerular filtration rate (eGFR) according to MDRD, serum creatinine and plasma urea of $5.0(3.0-8.0) \mathrm{ml} / \mathrm{min} / 1.73 \mathrm{~m}^{2}, 12.0(8.2-$ $17.8) \mathrm{mg} / \mathrm{dl}$ and 197 (147-288) $\mathrm{mg} / \mathrm{dl}$, respectively. The median values (IQR) of eGFR, serum creatinine and plasma urea of HD patients with and without preserved IUV (initial urine volume) were 6.0 (4.0-8.0) vs 4.0 (3.0$8.0) \mathrm{ml} / \mathrm{min} / 1.73 \mathrm{~m}^{2}(p=0.023), 11.0(8.0-16.0)$ vs 13.0 $(8.4-20.0) \mathrm{mg} / \mathrm{dl}(p=0.036)$ and $187(139-261)$ vs 223 $(168-331) \mathrm{mg} / \mathrm{dl}(p=0.004)$, respectively.

Patients with preserved initial RUV, compared to those with an initial RUV of less than $500 \mathrm{ml} /$ day, were often on diuretics (60\% vs $46 \%$, respectively; $p=0.032)$ and ACE inhibitors $(65.4 \%$ vs $44.7 \%$, respectively; $p=0.001)$. They had less hypervolemia (21.3\% vs $55.3 \%$, respectively; $p<0.001)$, hyperkalemia $(4.9 \pm 1.3$ vs $5.4 \pm 1.4 \mathrm{mEq} / \mathrm{l}$, respectively; $p=0.007$ ) and anemia ( $\mathrm{Hb} 8.8 \pm 2.2$ vs $8.2 \pm 2.2 \mathrm{~g} / \mathrm{dl}$, respectively; $p=0.042$ ). In addition, their serum albumin level was higher $(38.1 \pm 7.0$ vs $35.6 \pm 7.4 \mathrm{~g} / \mathrm{l}$, respectively; $p=0.007$ ).

\section{Evolution of urine volume in patients undergoing hemodialysis}

In total, 454 repeat measurements of RUV were performed in patients at three evaluation stages: 250 measurements (100\% of patients) at the initiation of HD, 127 $(50.8 \%)$ at 6 months and $77(30.8 \%)$ at 12 months from the start of HD. The RUV varied between 0 and $2740 \mathrm{ml} /$ day, with a median value (IQR) of $500 \mathrm{ml} /$ day (200-1000 ml/day).

Figure 1 shows that the population RUV decreased with time but with a slight deceleration. This trend is also observed at the individual level (Fig. 2). The mean RUV values were $680 \pm 537 \mathrm{ml} /$ day, $558 \pm 442 \mathrm{ml} /$ day and $499 \pm 475 \mathrm{ml} /$ day, respectively, at the initiation of $\mathrm{HD}$ and 6 and 12 months later.

\section{Urine volumes of patients according to their baseline characteristics}

Urine volume (median) decreased over time in all patients, except in non-hypertensive patients, whose urine volume tended to increase over time (Table 2). Roughly, at each assessment time, the median urine volume was higher in men than in women, in patients with hypovolemia, in those with chronic tubulointerstitial nephropathy, and in those treated with diuretics, ACE inhibitors and ARB compared to the others. On the other hand, urine volume was lower in diabetics and hypertensive patients (as of the 2nd assessment), patients with left ventricular hypertrophy or heart failure, and those with initially $\geq 3$ sessions of HD per week compared to the others. Urine volume was not correlated with age (Pearson $r=0.004$ ) or diastolic blood pressure (Pearson's r value $=-0.010$ ). 
Table 1 Clinical and biological characteristics of the patients at the initiation of hemodialysis

\begin{tabular}{|c|c|c|c|c|}
\hline \multirow[t]{2}{*}{ Variables } & \multirow{2}{*}{$\begin{array}{l}\text { All group } \\
n=250\end{array}$} & \multicolumn{2}{|c|}{ Initial urine volume (ml/day) } & \multirow[t]{2}{*}{$p$} \\
\hline & & $\begin{array}{l}\leq 500 \\
n=123\end{array}$ & $\begin{array}{l}>500 \\
n=127\end{array}$ & \\
\hline Age, years & $52.5 \pm 12.4$ & $52.1 \pm 13.3$ & $52.8 \pm 11.5$ & 0.683 \\
\hline Sex, female, n (\%) & $78(31.2)$ & $44(35.8)$ & $34(26.8)$ & 0.125 \\
\hline Diabetes mellitus, n (\%) & $98(39.2)$ & $48(39.0)$ & $50(39.4)$ & 0.955 \\
\hline $\mathrm{SBP}, \mathrm{mm} \mathrm{Hg}$ & $153.8 \pm 27.2$ & $153.4 \pm 27.3$ & $154.1 \pm 27.3$ & 0.821 \\
\hline $\mathrm{DBP}, \mathrm{mm} \mathrm{Hg}$ & $84.7 \pm 18.3$ & $84.0 \pm 17.5$ & $85.2 \pm 19.1$ & 0.604 \\
\hline $\mathrm{PP}, \mathrm{mm} \mathrm{Hg}$ & $69.1 \pm 20.8$ & $69.4 \pm 19.9$ & $68.9 \pm 21.8$ & 0.861 \\
\hline Hypertension, n (\%) & $217(86.8)$ & $104(84.6)$ & $113(89.0)$ & 0.302 \\
\hline Diuretics, n (\%) & $133(53.2)$ & $57(46.3)$ & $76(59.8)$ & 0.032 \\
\hline ACE inhibitors, n (\%) & $138(55.2)$ & $55(44.7)$ & $83(65.4)$ & 0.001 \\
\hline ARB, n (\%) & $29(11.6)$ & $12(9.8)$ & $17(13.4)$ & 0.370 \\
\hline Hypovolemia, n (\%) & $40(16.0)$ & $12(9.8)$ & $28(22.1)$ & 0.008 \\
\hline Hypervolemia, n (\%) & $95(38.0)$ & $68(55.3)$ & $27(21.3)$ & $<0.001$ \\
\hline eGFR-MDRD, ml/min/1.73 m² & $\begin{array}{l}5.0(3.0-8.0) \\
(n=240)\end{array}$ & $\begin{array}{l}4.0(3.0-8.0) \\
(n=115)\end{array}$ & $\begin{array}{l}6.0(4.0-8.0) \\
(n=125)\end{array}$ & 0.023 \\
\hline Serum creatinine, mg/dl & $\begin{array}{l}12.0(8.2-17.8) \\
(n=240)\end{array}$ & $\begin{array}{l}13.0(8.4-20.0) \\
(n=115)\end{array}$ & $\begin{array}{l}11.0(8.0-16.0) \\
(n=125)\end{array}$ & 0.036 \\
\hline Serum urea, mg/dl & $\begin{array}{l}197(147-288) \\
(n=239)\end{array}$ & $\begin{array}{l}223(168-331) \\
(n=115)\end{array}$ & $\begin{array}{l}187(139-261) \\
(n=124)\end{array}$ & 0.004 \\
\hline Serum potassium, $\mathrm{mmol} / \mathrm{l}$ & $\begin{array}{l}5.2 \pm 1.4 \\
(n=239)\end{array}$ & $\begin{array}{l}5.4 \pm 1.4 \\
(n=115)\end{array}$ & $\begin{array}{l}4.9 \pm 1.3 \\
(n=124)\end{array}$ & 0.007 \\
\hline Hemoglobin level, g/dl & $\begin{array}{l}8.5 \pm 2.2 \\
(n=249)\end{array}$ & $\begin{array}{l}8.2 \pm 2.2 \\
(n=122)\end{array}$ & $\begin{array}{l}8.8 \pm 2.2 \\
(n=127)\end{array}$ & 0.042 \\
\hline Proteinuria, g/24 h & $(n=77)$ & $(n=26)$ & $(n=51)$ & 0.343 \\
\hline$<1, \mathrm{n}(\%)$ & $22(28.6)$ & $6(23.1)$ & $16(31.4)$ & \\
\hline $1-3, n(\%)$ & $41(53.2)$ & $13(50.0)$ & $28(54.9)$ & \\
\hline$>3, \mathrm{n}(\%)$ & $14(18.2)$ & $7(26.9)$ & $7(13.7)$ & \\
\hline Serum albumin, $\mathrm{g} / \mathrm{l}$ & $\begin{array}{l}36.8 \pm 7.3 \\
(n=234)\end{array}$ & $\begin{array}{l}35.6 \pm 7.4 \\
(n=116)\end{array}$ & $\begin{array}{l}38.1 \pm 7.0 \\
(n=118)\end{array}$ & 0.007 \\
\hline Interstitial initial nephropathy, n (\%) & $23(9.2)$ & $9(7.3)$ & $14(11.0)$ & 0.311 \\
\hline Left ventricular hypertrophy, n (\%) & $\begin{array}{l}101(42.8) \\
(n=236)\end{array}$ & $\begin{array}{l}55(47.8) \\
(n=115)\end{array}$ & $\begin{array}{l}46(38.0) \\
(n=121)\end{array}$ & 0.200 \\
\hline Congestive heart failure, n (\%) & $86(34.4)$ & $47(38.2)$ & $39(30.7)$ & 0.212 \\
\hline$\geq 3$ times hemodialysis weekly, $\mathrm{n}(\%)$ & $116(46.4)$ & $60(48.8)$ & $56(44.1)$ & 0.458 \\
\hline
\end{tabular}

Data are expressed as the mean \pm standard deviation, median (interquartile range) or absolute frequency (relative frequency in percent)

Abbreviations: SBP systolic blood pressure, DBP diastolic blood pressure, $A C E$ angiotensin conversion enzyme, $A R B$ angiotensin receptor blockers, eGFR estimated glomerular filtration ratio, MDRD modification of diet in renal disease

\section{Factors significantly associated with the preservation/ decrease of urine volume ( $\mathrm{ml} /$ day) over time}

As the Table 3 shows, time has a significant quadratic effect on RUV. The negative beta coefficient (for time) shows that the average RUV decreased with time. The positive coefficient (for the quadratic term, time ${ }^{2}$ ) shows that there was a deceleration of this decline (the decline slowed down with time). The use of ACE inhibitors at the initiation of HD (beta coefficient of 219.5, $p<0.001$ ) and the presence of interstitial initial nephropathy (beta coefficient of 291.8, $p=0.007$ ) were the baseline characteristics significantly associated with the preservation of RUV over time. In contrast, the presence of left ventricular hypertrophy at the initiation of HD was significantly associated with decreased RUV over time (beta coefficient of $-133.9, p=0.029)$. There were no significant interactions between the time variable and the baseline characteristics of patients.

For the sensitivity analysis, the model in which the quadratic term of time was allowed as a random effect failed to converge. However, the model 2 containing an unstructured covariance matrix $(\mathrm{AIC}=6410.8$. $)$ provided 


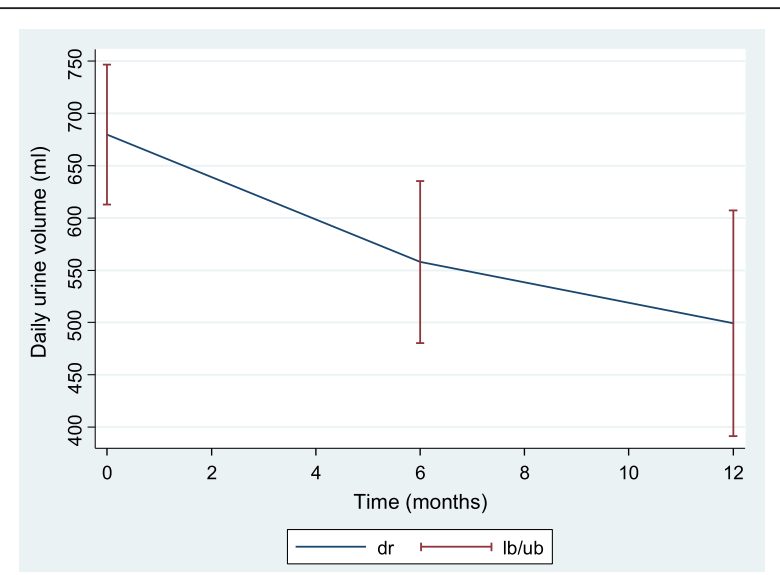

Fig. 1 Population means (95\% confidence interval bars) of residual urine volume at each assessment time

a better fit than those with the exchangeable (AIC = 6427.3) and the $\mathrm{AR}(1)(\mathrm{AIC}=6420.4)$ covariance structures.

Figure 3 shows the marginal average of VUR predicted by the model 2 and better displays the quadratic pattern of RUV over time.

\section{Discussion}

This study assessed predictors of RUV preservation in HD patients. The mean RUV at the initiation of HD was as high as $680 \mathrm{ml}$. This is significantly elevated compared to the data reported in the CHOICE study [31]. RUV was also better preserved in the present study than in the CHOICE study.

Indeed, one year after the initiation of $\mathrm{HD}, 60 \%$ of patients in this study still yielded $>250 \mathrm{ml} /$ day as opposed to $23.2 \%$ in the CHOICE study [31]. Numerous comorbidities and the more advanced ages of HD patients in Western countries could explain this difference.

When we analyze the effect of time alone, we note that the speed of the decline in RUV slowed down with time.

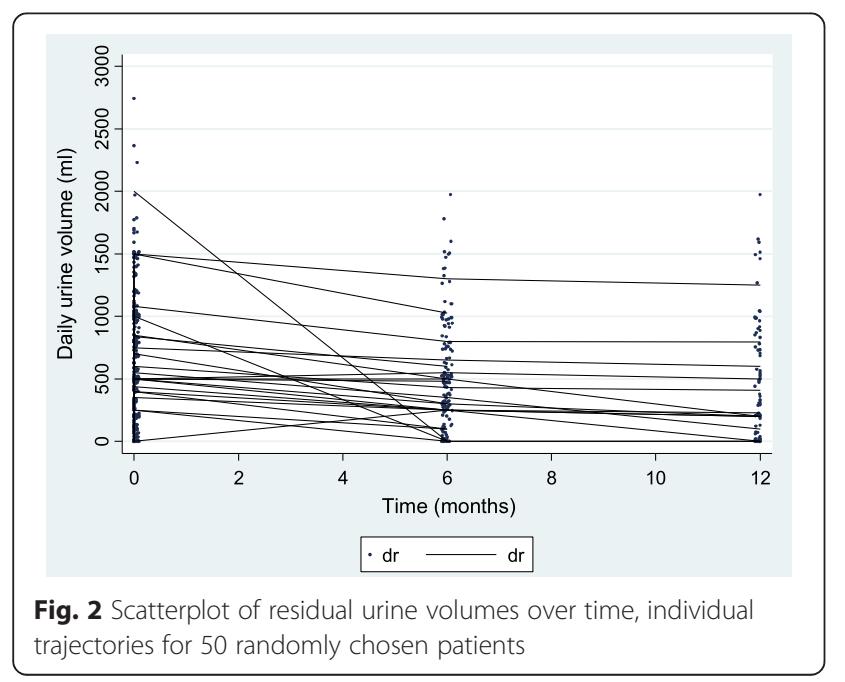

This effect remained present even after adjustments for ACE inhibitors use, chronic tubulointerstitial nephropathy and LVH in model 2. This slowing of the decline in urine volume with time could be attributed to an improvement in the technique of dialysis with the introduction of the HDF technique in the two study centers since 2010. HDF is characterized by a small decrease in RUV, similar to peritoneal dialysis.

The present study did not show an association between urine volume and age or sex. These results are contrary to those of the literature [4-7]. However, Nechita et al., in a study of a cohort of 216 patients with stage 5 chronic kidney disease (CKD) beginning chronic $\mathrm{HD}$, also failed to find a significant association between residual diuresis and age or sex [32]. It is possible that the small sample size did not reveal the influence of age or sex on the loss of urine volume. Another reason may be related to the fact that urine volume is the result of glomerular filtration, tubular reabsorption and the influence of diuretic therapy. In addition, in CKD, the concentration and dilution tubular capacity is altered as a result of tubulointerstitial fibrosis and increased tubular resistance by $\mathrm{ADH}[33,34]$.

In the present study, independent predictors of urine volume were the use of ACE inhibitors, chronic tubulointerstitial nephropathy and LVH.

The beneficial role of ACE inhibitors on RKF and RUV in HD has been demonstrated in the analysis of the U.S. Renal Data System data, a study of 2211 incident dialysis patients with RKF defined by UV > $200 \mathrm{ml} /$ day. This study found that the use of an ACE inhibitor was independently associated with a decreased risk of UV loss [5]. Several other studies have shown the benefit of ACE inhibitors on RKF and RUV in HD patients [3538]. The prospective study by Xydakis et al. proved that ACE inhibitors have a significant effect on preserving RKF in patients starting dialysis, at least during the first 12 months from the initiation of the HD, with RKF defined as residual GFR and RUV [18]. This beneficial effect of ACE inhibitors can be explained not only by the control of blood pressure parameters and by the antiproteinuric effect but also by their action against inflammation, malnutrition and glomerular and interstitial fibrosis linked to the deleterious action of angiotensin II [38]. In addition, blood contact with the HD filter membrane causes a cascade of reactions, including activation of mononucleated cells that are responsible for several inflammatory mediators, such as IL- $1_{\beta}$, IL-6, TNF $\alpha$, reactive oxygen species (ROS), and nitrogen monoxide, and the release of proteins from the acute phase of inflammation, such as $C$ reactive protein [38]. The use of ACE inhibitors decreases serum TNF alpha and $C$ reactive protein levels [39], resulting in a reduction in inflammation and oxidative stress and subsequently better 
Table 2 Evolution of urine volume ( $\mathrm{ml} /$ day) in patients undergoing hemodialysis according to baseline categorical characteristics

\begin{tabular}{|c|c|c|c|c|c|c|}
\hline & \multicolumn{2}{|c|}{ At initiation } & \multicolumn{2}{|c|}{ At 6th month } & \multicolumn{2}{|c|}{ At 12th month } \\
\hline & $n$ & Median (IQR) & $n$ & Median (IQR) & $n$ & Median (IQR) \\
\hline All patients & 250 & $550(200-1000)$ & 127 & $500(250-830)$ & 77 & $400(100-840)$ \\
\hline \multicolumn{7}{|l|}{ Sex } \\
\hline Male & 172 & $600(235-1008)$ & 93 & $500(250-800)$ & 53 & $410(158-773)$ \\
\hline Female & 78 & $500(200-1050)$ & 34 & $450(95-1000)$ & 24 & 300 (26-938) \\
\hline \multicolumn{7}{|l|}{ Diabetes mellitus } \\
\hline No & 152 & $535(250-1050)$ & 75 & $500(250-900)$ & 46 & $500(200-850)$ \\
\hline Yes & 98 & $550(190-1000)$ & 52 & $475(231-720)$ & 31 & $200(0-750)$ \\
\hline \multicolumn{7}{|l|}{ Hypertension } \\
\hline No & 33 & 500 (90-968) & 10 & $770(0-950)$ & 5 & $840(325-925)$ \\
\hline Yes & 217 & $600(250-1050)$ & 117 & $500(250-800)$ & 72 & $325(100-784)$ \\
\hline \multicolumn{7}{|l|}{ Diuretics } \\
\hline No & 117 & $500(135-1000)$ & 58 & $375(100-1000)$ & 36 & $325(0-888)$ \\
\hline Yes & 133 & 730 (325-1035) & 69 & $500(300-795)$ & 41 & $450(200-773)$ \\
\hline \multicolumn{7}{|l|}{ ACE inhibitors } \\
\hline No & 112 & $400(100-1000)$ & 44 & $350(100-875)$ & 27 & $275(0-795)$ \\
\hline Yes & 138 & $750(400-1051)$ & 83 & $500(300-830)$ & 50 & $500(200-863)$ \\
\hline \multicolumn{7}{|l|}{ ARB } \\
\hline No & 221 & $500(200-1000)$ & 112 & $500(250-800)$ & 65 & $400(100-795)$ \\
\hline Yes & 29 & $800(300-1060)$ & 15 & $650(350-900)$ & 12 & 455 (250-900) \\
\hline \multicolumn{7}{|l|}{ Hypovolemia } \\
\hline No & 210 & $500(200-1013)$ & 115 & $500(225-800)$ & 71 & $300(50-850)$ \\
\hline Yes & 40 & 800 (300-1038) & 12 & 710 (425-963) & 6 & $575(475-868)$ \\
\hline \multicolumn{7}{|c|}{ Interstitial initial nephropathy } \\
\hline No & 227 & $500(200-1000)$ & 119 & $500(250-800)$ & 72 & $325(100-773)$ \\
\hline Yes & 23 & $975(280-1490)$ & 8 & $900(750-1250)$ & 5 & $850(700-950)$ \\
\hline \multicolumn{7}{|c|}{ Left ventricular hypertrophy } \\
\hline No & 135 & $730(250-1100)$ & 70 & $500(250-900)$ & 45 & $400(200-875)$ \\
\hline Yes & 101 & $500(200-1000)$ & 49 & $450(100-840)$ & 31 & $350(0-750)$ \\
\hline \multicolumn{7}{|c|}{ Congestive heart failure } \\
\hline No & 164 & $610(200-1054)$ & 78 & $500(275-863)$ & 50 & $375(179-913)$ \\
\hline Yes & 86 & $500(238-1000)$ & 49 & $480(100-790)$ & 27 & $410(50-650)$ \\
\hline \multicolumn{7}{|c|}{ Initial hemodialysis characteristic } \\
\hline$\leq 2$ times weekly & 134 & $600(200-1000)$ & 62 & $500(300-863)$ & 30 & $455(100-843)$ \\
\hline$\geq 3$ times weekly & 116 & $500(200-1043)$ & 65 & $450(113-800)$ & 47 & $300(50-850)$ \\
\hline
\end{tabular}

Abbreviations: IQR interquartile range, $A C E$ angiotensin conversion enzyme, $A R B$ angiotensin receptor blockers

preservation of RKF and RUV. Kidney Disease Outcomes Quality Initiative guidelines currently recommend the use of ACE inhibitors in the preservation of RKF and in the control blood pressure in patients with RUVs in excess of $100 \mathrm{ml} \mathrm{[16].}$

The principal manifestations of TIN are those of tubular dysfunction. The tubulointerstitial lesions are localized either to the cortex or medulla. The extent of damage determines the severity of tubular dysfunction. Disruption of these structures, therefore, results in different degrees of nephrogenic diabetes insipidus and clinically manifests as polyuria and nocturia [33, 34]. A close correlation exists between the severity of chronic tubulointerstitial nephropathy and impaired renal tubular and glomerular function. Chronic tubulointerstitial nephropathy usually preserve the RUV more often in 
Table 3 Factors significantly associated with the preservation/decrease of residual urine volume (ml/day) over time

\begin{tabular}{|c|c|c|c|c|c|c|c|c|c|c|c|c|}
\hline & \multicolumn{3}{|c|}{ Model 1} & \multicolumn{3}{|c|}{ Model 2} & \multicolumn{3}{|l|}{ Model 3} & \multicolumn{3}{|c|}{ Model 4} \\
\hline & $\beta$ & SE & $p$ & $\beta$ & SE & $p$ & $\beta$ & SE & $p$ & $\beta$ & SE & $p$ \\
\hline Intercept & 679.6 & 33.5 & $<0.001$ & 595.7 & 55.9 & $<0.001$ & 595.1 & 55.3 & $<0.001$ & 595.6 & 55.6 & $<0.001$ \\
\hline Time (month) & -36.6 & 6.5 & $<0.001$ & -37.5 & 6.8 & $<0.001$ & -40.5 & 10.1 & $<0.001$ & -40.8 & 8.8 & $<0.001$ \\
\hline Time*time $\left(m o n t h^{2}\right)$ & 1.4 & 0.5 & 0.002 & 1.4 & 0.5 & 0.002 & 1.7 & 0.9 & 0.047 & 1.7 & 0.7 & 0.019 \\
\hline ACE inhibitors, yes vs no & & & & 219.5 & 62.1 & $<0.001$ & 237.5 & 62.5 & $<0.001$ & 236.2 & 62.7 & $<0.001$ \\
\hline Left ventricular hypertrophy, yes vs no & & & & -133.9 & 61.2 & 0.029 & -148.4 & 61.8 & 0.016 & -149.1 & 62.1 & 0.016 \\
\hline Interstitial initial nephropathy, yes vs no & & & & 291.8 & 108.9 & 0.007 & 256.8 & 108.1 & 0.018 & 262.4 & 108.6 & 0.016 \\
\hline
\end{tabular}

Model 1: Fixed effects: intercept, time, time ${ }^{2}$; Random effects: intercept, time; covariance structured: unstructured; AlC: 6756.8 . Model 2 (main model): model $1+$ baseline covariates (age, sex, diabetes mellitus, hypertension, diastolic blood pressure, diuretics, ACE inhibitors, angiotensin receptor blockers, hypovolemia, interstitial initial nephropathy, left ventricular hypertrophy and initial hemodialysis characteristic) as fixed effects; AIC: 6410.8 . Model 3: model 2 with exchangeable covariance structure; AIC: 6427.3. Model 4: model 2 with autoregressive residual (1) covariance structure; AIC: 6420.4 Abbreviation: ACE angiotensin conversion enzyme, SE standard error, AlC Akaike information criterion

this study. Tubular dysfunction probably justified the preservation of RUV in patients with chronic tubulointerstitial nephropathy [34].

$\mathrm{LVH}$ is an important predictor of cardiovascular mortality and morbidity in dialysis patients. Hypertension, diabetes, increased body mass index, gender, age, anemia, and hyperparathyroidism have been described as risk factors for LVH in HD patients [40]. LVH is also recognized in the literature as a predictor of the loss of RUV $[4,5,10]$. LVH was negatively correlated with RUV [40]. The results of our study corroborate the information described in the literature regarding the negative effect of LVH on RUV. The mechanisms by which LVH favors altered RUV are both hemodynamic and neurohormonal. Diastolic and/or systolic dysfunction decrease renal perfusion pressure and effective ultrafiltration pressure [10] and increase renal venous pressure and water and sodium retention, contributing substantially to the decline in RUV. In addition, sympathetic stimulation, renin-angiotensin-aldosterone system activation, inflammation, oxidative stress and endothelial dysfunction also contribute to alterations of RUV by renal fibrosis

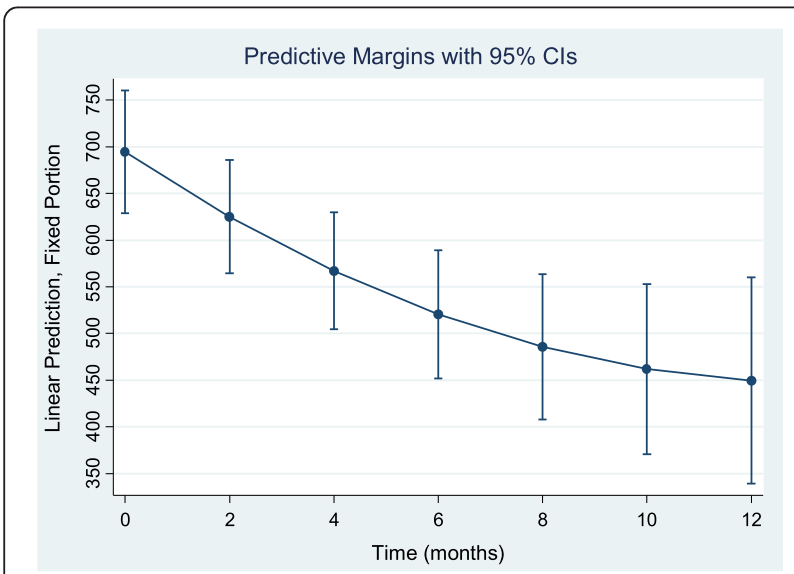

Fig. 3 Model 2 predicted marginal means of residual urine volumes (ml) over time with 95\% confidence intervals (Cls)
[41]. In CKD, a veritable vicious circle is established between LVH and RUV. The loss of RUV favors hypervolemia and elevated blood pressure, two factors that favor $\mathrm{LVH}$, which will exacerbate the loss of RUV by hypoperfusion. To combat $\mathrm{LVH}$, the use of ACE inhibitors is the treatment of choice. A comparison between ACE inhibitors and other drug controls showed that ACE inhibitors cause a greater reduction in LVH in HD patients [42]. Another strategy is to increase the duration and frequency of HD sessions [43]. If this strategy has the capacity to reduce RUV in conventional HD [13, 14], this is not the case in hemodiafiltration (HDF). High-efficiency post-dilution on-line HDF reduces LVH without altering RUV [44].

Given the influence of the time spent in HD on RUV, it is necessary to make efforts to improve the practice of HD. The quality of the water treatment (ultrapure water) [26], the use of biocompatible dialysates and dialyzers $[24,25]$, and the prevention of peridialytic hypotension $[5,7,11]$ must be taken into account.

The interpretation of the results of the present study should consider some limitations. First, the retrospective characteristic of the study design precludes the establishment of an all cause-effect relationship. Second, the small sample size did not confer much power to the statistical tests to identify additional associations. Without urine creatinine available, the accuracy of 24-h urine output in the present study could not be certified. However, despite these limitations, the present study is the first to evaluate independent predictors of RUV in Sub-Saharan Africa.

\section{Conclusion}

In the present study, the use of ACE inhibitors, chronic tubulointerstitial nephropathy and LVH reduction emerged as the main independent predictors of RUV preservation over time. The use of ACE inhibitors and HDF should be preferred for the optimal management of HD patients. 


\section{Abbreviations}

ACE: Angiotensin conversion enzyme; CKD: Chronic Kidney Disease; DBP: Diastolic blood pressure; eGFR: glomerular filtration rate; ESRD: End-stage chronic renal disease; HD: Hemodialysis; HDF: Hemodiafiltration; LVH: Left ventricular hypertrophy; MDRD: Modification of Diet in Renal Disease; P: Statistical significance; PP: Pulse pressure; RKF: Residual kidney function; RUV: Residual urine volume; SBP: Systolic blood pressure

\section{Acknowledgements}

The authors thank all members of the staff of the Hemodialysis Centers of Ngaliema Medical Center and General Referral Hospital of Kinshasa Province for their contribution to the present study. The authors also remain deeply indebted to all patients who allowed the study to be carried out with their consent.

\section{Funding}

This work received no financial assistance from any funding agency in the commercial, public or non-profit sectors.

\section{Availability of data and materials}

The datasets used and/or analyzed during the current study are available from the corresponding author on reasonable request.

\section{Authors' contributions}

VMM, EKS, FBL, JRM, JLL designed the study, acquired, analyzed; interpreted data, drafted and, revised the manuscript. FINM, JBB, PPI, SKM, DKM, NMN analyzed, interpreted data and revised the manuscript. VM Mokoli had full access to all the study data and assume responsibility for the integrity of the data and the accuracy of the analysis. All authors read, and approved the final manuscript

\section{Ethics approval and consent to participate}

The Ethics Committee of the Faculty of Medicine, University of Kinshasa approved the implementation of this study.

\section{Consent for publication}

Not applicable

\section{Competing interests}

The authors declare that they have no competing interests.

\section{Publisher's Note}

Springer Nature remains neutral with regard to jurisdictional claims in published maps and institutional affiliations.

\section{Author details}

'Division of Nephrology, University of Kinshasa, Kinshasa, Democratic Republic of the Congo. ${ }^{2}$ Hemodialysis Unit of Ngaliema Medical Center, Kinshasa, Democratic Republic of the Congo. ${ }^{3}$ Hemodialysis Unit of Provincial General Hospital of Kinshasa, Kinshasa, Democratic Republic of the Congo. ${ }^{4}$ School of Public Health, University of Kinshasa, Kinshasa, Democratic Republic of the Congo. ${ }^{5}$ Faculty of medicine, University of Kikwit, Kikwit, Democratic Republic of the Congo.

\section{Received: 27 May 2016 Accepted: 6 March 2018}

\section{Published online: 20 March 2018}

\section{References}

1. Sumaili EK, Krzesinski JM, Cohen EP, Nseka NM. Epidemiology of chronic kidney disease in the Democratic Republic of Congo: review of crosssectional studies from Kinshasa, the capital. Nephrol Ther. 2010;6(4):232-9.

2. Bargman JM. The CANUSA study and the importance of residual kidney function in dialysis patients. Kidney Int. 2010;77(10):931. author reply 931-932

3. Brener ZZ, Kotanko P, Thijssen S, Winchester JF, Bergman M. Clinical benefit of preserving residual renal function in dialysis patients: an update for clinicians. Am J Med Sci. 2010;339(5):453-6.

4. Obi Y, Rhee CM, Mathew AT, Shah G, Streja E, Brunelli SM, Kovesdy CP, Mehrotra R, Kalantar-Zadeh K. Residual Kidney Function Decline and Mortality in Incident Hemodialysis Patients. J Am Soc Nephrol. JASN 2016; 27(12):3758-68.

5. Moist LM, Port FK, Orzol SM, Young EW, Ostbye T, Wolfe RA, Hulbert-Shearon T, Jones CA, Bloembergen WE. Predictors of loss of residual renal function among new dialysis patients. J Am Soc Nephrol. 2000;11(3):556-64.
6. Singhal MK, Bhaskaran S, Vidgen E, Bargman JM, Vas SI, Oreopoulos DG. Rate of decline of residual renal function in patients on continuous peritoneal dialysis and factors affecting it. Perit Dial Int. 2000;20(4):429-38.

7. Zhang M, Wang M, Li H, Yu P, Yuan L, Hao C, Chen J, Kalantar-Zadeh K Association of initial twice-weekly hemodialysis treatment with preservation of residual kidney function in ESRD patients. Am J Nephrol. 2014:40(2):140-50.

8. Johnson DW, Mudge DW, Sturtevant JM, Hawley CM, Campbell SB, Isbel NM, Hollett P. Predictors of decline of residual renal function in new peritoneal dialysis patients. Perit Dial Int. 2003;23(3):276-83.

9. Menon MK, Naimark DM, Bargman JM, Vas SI, Oreopoulos DG. Long-term blood pressure control in a cohort of peritoneal dialysis patients and its association with residual renal function. Nephrol Dial Transplant. 2001; 16(11):2207-13.

10. Kim JK, Kim SG, Kim MG, Kim SE, Kim SJ, Kim HJ, Song YR. Left ventricular diastolic dysfunction as a predictor of rapid decline of residual renal function in patients with peritoneal dialysis. J Am Soc Echocardiogr. 2012; 25(4):411-20.

11. Jansen MA, Hart AA, Korevaar JC, Dekker FW, Boeschoten EW, Krediet RT. Predictors of the rate of decline of residual renal function in incident dialysis patients. Kidney Int. 2002;62(3):1046-53.

12. Lin YF, Huang JW, Wu MS, Chu TS, Lin SL, Chen YM, Tsai TJ, Wu KD. Comparison of residual renal function in patients undergoing twice-weekly versus threetimes-weekly haemodialysis. Nephrology (Carlton, Vic). 2009;14(1):59-64.

13. Daugirdas JT, Greene T, Rocco MV, Kaysen GA, Depner TA, Levin NW, Chertow GM, Ornt DB, Raimann JG, Larive B, et al. Effect of frequent hemodialysis on residual kidney function. Kidney Int. 2013;83(5):949-58.

14. Obi Y, Streja E, Rhee CM, Ravel V, Amin AN, Cupisti A, Chen J, Mathew AT, Kovesdy CP, Mehrotra R, et al. Incremental hemodialysis, residual kidney function, and mortality risk in incident Dialysis patients: a cohort study. Am J Kidney Dis. 2016:68(2):256-65.

15. Lang SM, Bergner A, Topfer M, Schiffl H. Preservation of residual renal function in dialysis patients: effects of dialysis-technique-related factors. Perit Dial Int. 2001;21(1):52-7.

16. National Kidney Foundation. $\mathrm{KDOQI}$ clinical practice guidelines for hemodialysis adequacy, update 2006. Am J Kidney Dis. 2006:48(Suppl 1):S2-90.

17. Yang PY, Lin JL, Lin-Tan DT, Hsu CW, Yen TH, Chen KH, Ho TC. Residual daily urine volume association with inflammation and nutrition status in maintenance hemodialysis patients. Ren Fail. 2009:31(6):423-30.

18. Xydakis D, Papadogiannakis A, Sfakianaki M, Kostakis K, Stylianou K, Petrakis I, Ergini A, Voskarides K, Dafnis E. Residual renal function in hemodialysis patients: the role of angiotensin-converting enzyme inhibitor in its preservation. ISRN nephrology. 2013;2013:184527.

19. Cravedi P, Remuzzi $G$, Ruggenenti P. Targeting the renin angiotensin system in dialysis patients. Semin Dial. 2011;24(3):290-7.

20. Bragg-Gresham JL, Fissell RB, Mason NA, Bailie GR, Gillespie BW, Wizemann V, Cruz JM, Akiba T, Kurokawa K, Ramirez S, et al. Diuretic use, residual renal function, and mortality among hemodialysis patients in the Dialysis outcomes and practice pattern study (DOPPS). Am J Kidney Dis. 2007:49(3):426-31.

21. Coronel F, Perez Flores I. Factors related to loss of residual renal function in peritoneal dialysis. Nefrologia. 2008;28(Suppl 6):39-44.

22. Drechsler C, de Mutsert R, Grootendorst DC, Boeschoten EW, Krediet RT, le Cessie S, Wanner C, Dekker FW. Association of body mass index with decline in residual kidney function after initiation of dialysis. Am J Kidney Dis. 2009;53(6):1014-23.

23. Chandna SM, Farrington K. Residual renal function: considerations on its importance and preservation in dialysis patients. Semin Dial. 2004;17(3):196-201.

24. Termorshuizen F, Dekker FW, van Manen JG, Korevaar JC, Boeschoten EW Krediet RT. Relative contribution of residual renal function and different measures of adequacy to survival in hemodialysis patients: an analysis of the Netherlands cooperative study on the adequacy of Dialysis (NECOSAD)-2. J Am Soc Nephrol. 2004;15(4):1061-70.

25. McKane W, Chandna SM, Tattersall JE, Greenwood RN, Farrington K. Identical decline of residual renal function in high-flux biocompatible hemodialysis and CAPD. Kidney Int. 2002;61(1):256-65.

26. Ward RA. Ultrapure dialysate. Semin Dial. 2004;17(6):489-97.

27. Mathew AT, Fishbane S, Obi Y, Kalantar-Zadeh K. Preservation of residual kidney function in hemodialysis patients: reviving an old concept. Kidney Int. 2016:90(2):262-71.

28. Truijen J, Bundgaard-Nielsen M, van Lieshout JJ. A definition of normovolaemia and consequences for cardiovascular control during orthostatic and environmental stress. Eur J Appl Physiol. 2010;109(2):141-57. 
29. Di Lullo L, Gorini A, Russo D, Santoboni A, Ronco C. Left ventricular hypertrophy in chronic kidney disease patients: from pathophysiology to treatment. Cardiorenal Med. 2015;5(4):254-66.

30. Punnoose LR, Givertz MM, Lewis EF, Pratibhu P, Stevenson LW, Desai AS. Heart failure with recovered ejection fraction: a distinct clinical entity. J Card Fail. 2011;17(7):527-32.

31. Shafi T, Jaar BG, Plantinga LC, Fink NE, Sadler JH, Parekh RS, Powe NR, Coresh J. Association of residual urine output with mortality, quality of life, and inflammation in incident hemodialysis patients: the choices for healthy outcomes in caring for end-stage renal disease (CHOICE) study. Am J Kidney Dis. 2010;56(2):348-58.

32. Nechita AM, Radulescu D, Peride I, Niculae A, Bratu O, Ferechide D, Ciocalteu A, Checherita IA, Mischianu D. Determining factors of diuresis in chronic kidney disease patients initiating hemodialysis. J Med Life. 2015;8(3):371-7.

33. Jensen JM, Mose FH, Kulik AE, Bech JN, Fenton RA, Pedersen EB. Abnormal urinary excretion of NKCC2 and AQP2 in response to hypertonic saline in chronic kidney disease: an intervention study in patients with chronic kidney disease and healthy controls. BMC Nephrol. 2014;15:101.

34. Ellison DH, Berl T. Clinical practice. The syndrome of inappropriate antidiuresis. N Engl J Med. 2007;356(20):2064-72.

35. Vilar E, Farrington K. Emerging importance of residual renal function in endstage renal failure. Semin Dial. 2011;24(5):487-94.

36. Costea AC, Costea DO, David C, Grasa CN. Role of ACE inhibitors in the management of arterial hypertension of hemodyalised patients. Rev Med Chir Soc Med Nat lasi. 2010;114(1):29-33.

37. Ryckelynck JP, Goffin E, Verger C. Maintaining residual renal function in patients on dialysis. Nephrol Ther. 2013;9(6):403-7.

38. Taal MW, Brenner BM. Renoprotective benefits of RAS inhibition: from ACE to angiotensin II antagonists. Kidney Int. 2000;57(5):1803-17.

39. Stenvinkel P, Andersson P, Wang T, Lindholm B, Bergstrom J, Palmblad J, Heimburger O, Cederholm T. Do ACE-inhibitors suppress tumour necrosis factor-alpha production in advanced chronic renal failure? J Intern Med. 1999:246(5):503-7.

40. Oguz EG, Gursoy GK, Yayar O, Yildirim T, Cimen T, Bulut C, Eser B, Canbakan $B$, Yeter $E$, Ayli MD. Increased serum renalase in hemodialysis patients: is it related to left ventricular hypertrophy? Ren Fail. 2016;38(8):1180-6.

41. Kingma JG Jr, Simard D, Rouleau JR. Renocardiac syndromes: physiopathology and treatment stratagems. Can J Kidney Health Dis. 2015;2:41.

42. Yang $Y$, Wang $R$, Li MX, Xing Y, Li WG. Effects of angiotensin-converting enzyme inhibitors and angiotensin receptor blockers on left ventricular mass index and ejection fraction in hemodialysis patients: a meta-analysis with trial sequential analysis of randomized controlled trials. Int J Cardiol. 2016;219:350-7

43. McCullough PA, Chan CT, Weinhandl ED, Burkart JM, Bakris GL. Intensive hemodialysis, left ventricular hypertrophy, and cardiovascular disease. Am J Kidney Dis. 2016;68(5s1):S5-s14.

44. Schiffl H, Lang SM, Fischer R. Effects of high efficiency post-dilution on-line hemodiafiltration or conventional hemodialysis on residual renal function and left ventricular hypertrophy. Int Urol Nephrol. 2013;45(5):1389-96.

\section{Submit your next manuscript to BioMed Central and we will help you at every step:}

- We accept pre-submission inquiries

- Our selector tool helps you to find the most relevant journal

- We provide round the clock customer support

- Convenient online submission

- Thorough peer review

- Inclusion in PubMed and all major indexing services

- Maximum visibility for your research

Submit your manuscript at www.biomedcentral.com/submit

C Biomed Central 